\title{
Components of Motivation to Learn from a Psychological Perspective
}

\author{
Anita Muho \\ "Aleksander Moisiu" University Durres, Albania \\ E-mail: anitamuho@yahoo.it \\ Aida Kurani \\ "Aleksander Moisiu" University Durres, Albania \\ E-mail: kuraniaida@hotmail.com
}

Doi:10.5901/ajis.2012.v2n4p173

\section{Abstract.}

This study aims at analyzing the components of motivation, which influence the learning process from a psychological perspective. The literature review serves as the background for the study conducted in three high schools of Durres, Albania. In the second part, this study discusses students, teachers understanding, and perceptions of these components and then explores which one of them, if any, they interpreted as the most influential factor to their perceptions of motivation. The findings show that components of motivation should not be considered independently, thus they overlap with one another as shown in the eight small circles. Within the third part of our study, we introduce a reconceptualization of motivation to learn which will possibly provide additional insights in better identifying existing motivational challenges and taking realistic perspectives about the English as a Foreign Language.

Keywords: Components, motivation, perspective, psychological, student.

\section{Introduction}

The enhancement of student motivation is an issue of major concern to teachers and education researchers. In Albania, educators are concerned about the low motivation level of students in learning a second language. Their students have little interest in class, fail to remember what their teachers had said, performed poorly academically and had no desire to improve. Teachers indicated they felt rather helpless realizing their students not gaining anything from their school life. We discuss students' understanding and perceptions of these components how different students interpreted these components from their own perspective. We explore which one of them, if any, they interpreted as the most influential factor to their perceptions of motivation.

Within the last part of this study, we introduce a reconceptualization of motivation to learn which will possibly provide additional insights in better identifying existing motivational challenges and taking realistic perspectives about the EFL. A thorough understanding of learner motivation could make significant contribution to the educational field.

\section{Literature review}

Harlen and Deakin-Crick, 2002) proposes that motivation to learn includes components of motivation such as 'effort', 'goal orientation', 'locus of control', 'self-efficacy', 'sense of self as learner', 'self-esteem', 'selfregulation' and 'interest'. Taking this framework as the core and referring to research and literatures, schools of thought and findings by other scholars, these motivation components are elaborated below: 


\subsection{Effort}

Effort can be defined as how much one is prepared to try to persevere in a task. If learners are motivated, they should invest more effort into learning and be more willing to try even when faced with difficulties and setbacks. Instead of giving up when confronted with difficulties, learners will try again to accomplish a task. Effort is one of the many motivating elements for learners, however, the amount of effort a learner invests is dependent on and influenced by various factors, including for example, the interest one develops, the level of commitment one intends to put and the confidence one has.

\subsection{Goal orientation}

Meece, Blumenfeld, and Hoyle (1988) define goal orientation as the set of behavioral intentions, determining how students approach and engage in learning activities. Wentzel (1989) defines goals as what students generally want to achieve in their classes, no matter it is academic or social. This belief extends the scope of the goal orientation beyond academic achievement, emphasizing the importance of the social aspects of a goal. The following categories elaborate how goal orientation can be identified:

Ego or social goals Meece, Blumenfeld, and Hoyle (1988) note that student goals are designed to demonstrate high ability or please the teacher. This is defined as ego or social goals. This extends the definition given by Wentzel (1989) above as the social goal is related to how learners gain recognition from teachers. Work avoidant goal Learners with work avoidant goals have the priority to get work done with the minimum amount of effort (Meece, Blumenfeld, and Hoyle, 1988). Students of this kind are likely to have little or no intrinsic motivation for the learning activity.

Jalongo (2007) explains that 'intrinsic motivation resides within the learner and the learning activity is rewarding in it because it is interesting, exciting, challenging, and so forth' ( $p .400)$. If students find the learning activity somewhat attractive, they are supposed to have the initiative to invest more effort into it. It implies that learners who tend to invest only the minimum effort on a particular task should have a comparatively low level of intrinsic motivation.

\subsubsection{Task goal/ Learning goal/ Mastery goal}

Kroll and Ford (1992) argue that students may orient to achieve task goals, which implies that the focus is on the task. This means a less important role played by one's own ability or effort relative to others. Greene and Miller (1996) refer to task goals as learning goals. They define it as the interest in learning and the purpose is to acquire and improve one's knowledge and skills. Miller, Behrens, Greene and Newman (1993) hold a similar belief and assert that learning goals are primarily concerned with acquiring new skills or improving their knowledge, even if it means making some errors along the way. These definitions show how learners strive to learn in order to acquire knowledge through the mastery of a particular task. Some scholars use task goals and learning goals interchangeably, some even add the term mastery goals. Meece, Blumenfeld and Hoyle (1988) refer to task goals as mastery goals where students independently master and understand their work.

\subsection{Locus of control}

Locus of control implies how much one feels in control of learning as opposed to it being directed by others. Others include teachers, parents or social pressure. It is better if learners can develop the ownership of learning and turn assessment into a learning event, as Konold, Miller and Konold (2004) suggest. That is, students need to develop appropriate strategies to improve their performance. Although learners may receive support in the process of the development of learning strategies, the learners themselves better hold the ownership of the learning activity. This emphasizes the importance of introducing self- and peer-assessment 
to learners because it not only boosts confidence, but also enhances their locus of control, giving them a sense of ownership in the learning process.

\section{Self-efficacy}

Self-efficacy is concerned with the judgments about how well a learner can organize and execute courses of action required to deal with situations containing many ambiguous, unpredictable, and often stressful elements (Bandura and Schunk, 1981). In this definition, self-efficacy is closely related to confidence as to how one perceives one's ability directly affects that judgment. Confidence in succeeding in a learning or assessment task is one of the components that motivate learners. It is a determining factor affecting a learner's perception of his or her level of competency in achieving a particular task. Bandura (1986) adds that individuals with low self-efficacy will tend to avoid activities they believe are beyond their capabilities, so they selectively choose easier tasks where the chances for success are greater.

\subsection{Sense of self as a learner}

Covington's (2000) illustration of intrinsic motivation brings some insight into the understanding of how to enhance the sense of oneself as a learner. Covington (2000) explains under what circumstances learners are more likely to value what they are learning and enjoy the learning process. He has given three conditions for this to happen.

First, Covington (2000) believes that even when feedback is given in the form of a grade, students can still be intrinsically motivated. The condition is that students have a task-oriented purpose in striving for high grades (e.g. if they use grades as feedback for how they can improve and learn more), then they will appreciate their accomplishments for their positive properties' (p.24). In fact, this coincides with Kroll and Ford (1992), Greene and Miller (1996), Miller et al. (1993) and Meece et al. (1988) regarding the discussion of goal orientation. The key lies with how students define their learning in the beginning because 'students' valuing of what they learn depends on their initial reasons for learning and the meaning they attach to their grades' (Covington, 2000, p.24). In other words, if learners have a task/ learning/ mastery goal orientation, it is more likely that they will attach a learning purpose to the grade and thus tend to value what will be learnt.

Second, Covington (2000) explains that one would likely value what they are learning if the learner feels successful. He asserts that 'being successful in one's studies promotes an appreciation for what one is learning' (p.24). Feeling successful, learners are more likely to become intrinsically engaged in their schoolwork. They would then value and enjoy the learning process, and develop their sense of self as learners.

Third, Covington (2000) observes that people enjoy learning more about what already interests them and students tend to 'make school more interesting by deliberately seeking out what is of interest to them, even in the case of boring assignments, or arranging a course of study' (p.24). Considering this, when giving feedback, teachers may explore students' interest and suggest activities that interest students. This can be done ahead of feedback-giving practice when tasks are designed in a way to make the assessment more interesting.

To conclude, it is more likely that learners will develop a sense of self as learners and enjoy the learning process if they are oriented toward a task goal; when they feel successful and if the task or assessment is of interest to them.

\subsection{Self-esteem}

According to Cast and Burke (2002), self-esteem refers to 'an individual's overall positive evaluation of the self' (p.1042). It is composed of two distinct dimensions, competence and worth. For the former, it is efficacy- 
based; and it refers to the degree to which people perceive themselves as capable and efficacious. For the latter, it is worth-based; and it refers to the degree to which individuals feel they are persons of value.

Among all the elements of motivation, self-esteem is of one of the greatest importance because there has been clear support in research literature for the 'positive relationship between student motivation and selfesteem to academic achievement and school success' (Nichols, 1998, p.272). Marsh (1990) argues that students with greater self-esteem are more likely to be successful academically in school.

The questions then are 'how is students' self-esteem boosted?' or more specifically, 'how can teachers build and help students build their self-esteem?' Some suggestions have been given by teachers in the English Journal (1992) in a round table discussion on the topic - Balancing self-esteem and rigorous academic standard. For instance, it is emphasized that teachers should never lie to students to make them feel good about themselves. It is also suggested that teachers should keep their evaluation as nonthreatening as possible and it is important not to underestimate students' intelligence. It also helps build students' self-esteem if they feel free to express varying opinions and are encouraged to have active involvement in class discussions (Reinert and Jennerjohn, 1992).

\subsection{Self-regulation}

As Brindley (1989) argues, self-assessment is a skill, which needs to be learnt. This process involves both 'technical training' (equipping learners with the skills to be able to judge their own performance) and 'psychological training' (preparing learners to take on more responsibility for their own learning) (p.78).

Psychological training is possibly the more difficult task for the teacher since it may involve a fundamental and profound shift of the learner's attitude toward learning, and their understanding of the roles of teachers and learners respectively. If this is achieved, not only are learners' self-regulation skills enhanced, but also their sense of self as learners. More importantly, motivation can be enhanced: 'self-evaluation is a major mechanism for building intrinsic motivation. If learners exercise control over when to move on to the next challenge, it helps to build confidence and avert failure' (Jalongo, 2007, p.405).

\subsection{Interest}

Many scholars distinguish personal or individual interest from situational interest. As Schraw, Bruning and Svoboda (1995) describe, personal interest is unique to the individual. It is topic specific, not short-lived, and exists prior to encountering a particular text. It is more enduring and emerges from one's history of interactions with certain topics. The implication is if one is interested and curious in the subject material and prefers challenges, one is likely to be intrinsically motivated for that particular task (Harter and Jackson, 1992).

Covington (2000) has also related personal interest and intrinsic motivation. He suggests that such motivation is built upon the 'satisfaction derived from overcoming a personal challenge, learning something new, or discovering things of personal interest' (p.23). On the other hand, Schraw et al. (1995) defines situational interest as the kind of interest that is more common across individuals, not long lasting, and elicited within a particular context. Compared with personal interest, it is more ad hoc and temporary in nature. It is specific to a particular context instead of unique to the individual. As Jalongo (2007) argues, situational interest is generally accepted to precede individual interest and situational interest is a major way of transferring interest from one task to a general interest. This can then pave the way for eliciting intrinsic motivation from students.

\section{Research methodology}

\subsection{Setting and participants}

This study was undertaken in three high schools of Durres, Albania. There were 400 students and 10 English 
teachers' part of this study. The schools use Albanian as the medium of instruction and English as a second language.

\subsection{Instruments for data collection}

Instruments for data collection include interviews, questionnaires and teachers' reflections. Interviews were one of the major sources of data in this study.

"Teachers have always reflected on their teaching before, during and after a particular teaching episode - its part of our professional disposition. Action research is no different... Pausing to analyze and reflect during the action research process is essential." (Mills, 2003).

\subsection{Data analysis}

In the first stage of data analysis, data are first presented in relation to students' perceptions of motivational components from a psychological perspective. Components are identified as to what drives students to learn. Both qualitative and quantitative data collected from questionnaires and students' interviews are presented following this framework. To answer the research question 'What are the motivational components from a psychological perspective?" data was extracted from the interviews conducted with students, student's reflections to explore how they perceived motivational components and in particular, their influence in the learning process. It was hoped that insight could be drawn in areas such as students' expectations of themselves, their perceptions of their own ability and effort expenditure, their responsibility in the learning process.

\section{Findings and discussion}

This research used baseline data collected from the students of different classes using English as a second language. It serves to provide a more reliable view of what components of motivation influence students to learn. As elaborated in the literature review motivation to learn includes components of motivation such as 'self-efficacy', 'self-esteem', 'self-regulation' ,'effort', 'goal orientation', 'locus of control', 'sense of self as learner', and 'interest'. In the questionnaires, students responded as to how strongly they agreed with statements related to the effect

\subsection{Effort}

When asked about how they treated teachers' feedback, some students responded that it was a matter of habit:

"We just stick to our own habits. We will not do those things usually, so we are motivated to put them (the feedback) into practice. We are used to not doing so and won't do so for any reason."

From this response, students tended to perceive 'effort' as a habitual thing. One student commented that there was a correlation between effort expenditure and expectation:

"If I have studied more, I might achieve a higher level (in my result)".

\subsection{Goal orientation}

In the interviews, students commented that there was a relationship between teacher feedback and goal orientation, stressing the importance of how a certain goal orientation would drive them to learn: 
Interviewer: That means you know that it is right to do what the teacher has told you to do but you do not have the motivating force. What can push you? Where is the initiative from?'

Student: There should be a goal. There should be a goal.

From this extract, it can be inferred that students agreed that there must be a goal to drive them to take action of what teachers ask them to do. In response to the different kinds of goals discussed in the literature review, students shared different ideas about their goals in mind.

\subsection{Locus of control}

When asked to try to define 'control' in the interviews, students responded that they did not really have this sense of control:

Interviewer: What do you understand by control?

Student: She asks and we answer. She asks and we answer. That is control.

The above response shows that students felt that they could not ask questions whenever they wanted to.

\subsection{Self-efficacy}

The students were asked to use their own words to describe how they understood the motivation component of self-efficacy and they related it to recognition:

Student: If you have done something, which wins the praise from the others, then you are capable of doing that task.

The above extract demonstrated that students tended to relate the praise they received on students' ability and achievement to their self-efficacy. They also tended to compare their own performance with their peers, demonstrating the influence of peers as significant others.

\subsection{Self-esteem}

Self-esteem is a rather abstract term and students were asked to say how they understood it in the interviews. They commented that being humiliated in front of a large crowd could hurt their self-esteem:

Interviewer: Just, we tend to get some samples of praise. To provide praise is for strengthening your selfesteem. How does one perceive self-esteem? You will use your language or examples to say. It is terribly abstract when there is no model answer.

Student: Not making you feel embarrassed. If you are criticizing in front of the class, you will be extremely hurt.

The above extract showed how student respondents thought that their peers could influence their self-esteem.

\subsection{Self-regulation}

In the interviews, students shared the difficulties they had encountered in self-regulation after receiving the feedback from teachers. They responded that sometimes the teacher feedback was too vague and not concrete enough, as it did not tell them exactly how they could improve: 
"Maybe the teacher points out the matter however rarely talks concerning the answer. For instance, if the teacher says that the pronunciation is not correct. Then after communicating this, the teacher jumps to a different part and does not tell the way to correct the pronunciation. This could be the problem."

\subsection{Interest}

Interest is another key motivation component. In the interview, some students suggested listening to English songs, reading English books and fictions:

Student: When I read an English magazine, I have difficulties understanding it. Therefore, I would like to learn.

Not surprisingly, students found that it would be more enjoyable to relate what they have learnt to their own interests. The suggestions provided above give insight into teaching practice.

\section{Conclusions}

The theoretical framework proposed above suggests that student motivation to learn includes components such as 'effort', 'goal orientation', 'locus of control', 'self-efficacy', 'sense of self as learner', 'self-esteem', 'selfregulation' and 'interest'.

The findings have shown that students gave various responses about how they perceived motivation. However, these motivational components are all very abstract with no commonly agreed or fixed definitions. Therefore, it is important to explore how different students interpreted these components from their own perspective. They also found some of the definitions of the terms blurry when they commented that they could not distinguish the difference among some of them (confidence and self-esteem). It is suggested that students are motivated at the individual level through eight interrelated motivation components. These components should not be considered independently, thus they overlap with one another as shown in the eight small circles.

This study identified teacher influence as the most crucial and core factor in affecting student motivation to learn. This has impact on other motivation components developed at the level of an individual learner, such as their effort expenditure, interest and self-esteem. More specifically, this study explored a reconceptualization of motivation to learn at the level of an individual learner from a psychological perspective. These findings will provide additional insights in better identifying existing motivational challenges and taking realistic perspectives about the EFL.

\section{References}

Ames, C. (1992). Classrooms: goals, structures, and student motivation. Journal of Education Psychology, 84 (3), 261-271. Bandura, A. (1977). Self-efficacy: toward a unifying theory of behavioral change. Psychological Review, 84, 191-215.

Bandura, A., Adams, N. and Beyer, J. (1977). Cognitive processes mediating behavioral change. Journal of Personality and Social Psychology, 35 (3), 125-139.

Bandura, A. and Schunk, D. (1981). Cultivating competence, self-efficacy, and intrinsic interest through proximal selfmotivation. Journal of Personality and Social Psychology, 41, 586-598.

Bouffard, T., Boisvert, J., Vezeau, C., and Larouche, C. (1995). The impact of goal orientation on self-regulation and performance among college students. British Journal of Educational Psychology, 65, 317-329.

Brophy, J. (1987). On motivating students. In D. Berliner and B. Rosenshine (Eds.) Talks to teachers. New York: Random House.

Brown, H. D. (1994). Teaching by principles. Englewood Cliffs, NJ: Prentice Hall.

Butler, R. (1993). Effects of task- and ego-achievement goals on information seeking during task engagement. Journal of Educational Psychology, 65, 18-31.

Cast, A. and Burke, P. (2002). A theory of self-esteem. Social Forces, 80 (3), 1041-1068. 
Covington, M. V. (1984). The self-worth theory of achievement motivation: findings and implications. Elementary School Journal, 85, 5-20.

Dörnyei, Z. (1994a). Understanding L2 motivation: on with the challenge. The Modern Language Journal, 78, 515-523.

Dörnyei, Z. (1994b). Motivation and motivating in the foreign language classroom. The Modern Language Journal, 78, 273284.

Dörnyei, Z. (2001a). Motivational strategies in the language classroom. Cambridge: Cambridge University Press.

Dörnyei, Z. (2001b). The psychology of the language learner. Mahwah, NJ: Lawrence Erlbaum.

Meece, J. L., Blumenfeld, P. C. and Hoyle, R. (1988). Students' goal orientations and

cognitive engagement in classroom activities. Journal of Educational Psychology, 80, 514-523.

Miller, R. B., Behrens, J. T., Greene, B. A. and Newman, D. (1993). Goals and perceived ability: impact on students valuing, self-regulation, and persistence. Contemporary Educational Psychology, 18, 2-14.

Murphy, P. K. and Alexander, P. A. (2000). A motivated exploration of motivation terminology. Contemporary Educational Psychology, 25, 3-53.

Nichols, J. (1998). An alternative learning program: effects on student motivation and self-esteem. The Journal of Educational Research, 91 (5), 272-278.

Nichols, J. and Miller, R. (1994). Cooperative learning and student motivation. Contemporary Educational Psychology, 19 (2), 167-178.

Pintrich, P. R. (2003). A motivational science perspective on the role of student motivation in learning and teaching contexts. Journal of Educational Psychology, 95 (4), 667-686.

Reinert, M. and Jennerjohn, M. (1992). Balancing self-esteem and rigorous academic standards. English Journal, 81 (3), 74-81.

Ryan, R.M. and Deci, E. L. (2000). Self-determination theory and the facilitation of intrinsic motivation, social development, and well-being. American Psychologist, 55 (1), 68-78.

Schraw, G., Bruning, R. and Svoboda, C. (1995). Sources of situational interest. Journal of Reading Behavior, 27, 1-17.

Schunk, D. H. (2000). Coming to terms with motivation constructs. Contemporary Educational Psychology, 25, 116-119.

Seifert, T. L. (2004). Understanding student motivation. Educational research, 46 (2), 137-149.

Stipek, D. (2002). Motivation to learn: integrating theory and practice. Needham Heights, MA: Allyn and Bacon.

Weiser, I. (2000). Self-assessment, reflection, and the new teacher of writing. In J. Smith and K. Yancey (Eds.) Self assessment and development in writing. (139-156). Cresskill, NJ: Hampton.

Wellington, J. (2000). Educational research: contemporary issues and practical approaches. London and New York: Continuum. 